\title{
Development of Screen-Printed Electrode Biosensor for Rapid Determination of Triglyceride Content in Coconut Milk
}

\author{
D. Manoj, Ishita Auddy, Shubham Nimbkar, S. Chittibabu, and S. Shanmugasundaram \\ Indian Institute of Food Processing Technology, Thanjavur, 613005 Tamil, India
}

Correspondence should be addressed to S. Shanmugasundaram; sasu@iifpt.edu.in

Received 1 October 2019; Accepted 17 March 2020; Published 7 May 2020

Academic Editor: Muhammad Jahangir

Copyright @ 2020 D. Manoj et al. This is an open access article distributed under the Creative Commons Attribution License, which permits unrestricted use, distribution, and reproduction in any medium, provided the original work is properly cited.

\begin{abstract}
The screen-printed electrode biosensor was developed for triglyceride determination in coconut milk. The biosensor was developed by adding lipase, glycerol-3-phosphate (GPO), and glycerol kinase (GK), which is immobilized to a gelatin solution. The concentration of triglyceride is found to be linear to the current produced. The developed screen-printed electrode biosensor showed the optimum response for $\mathrm{pH} 7.0,45 \mathrm{mg}$ amount of gelatin, 2.5\% glutaraldehyde concentration solution. The developed biosensor was able to find triolein concentrations 0.1 to $1.5 \mathrm{mM}$. The correlation obtained between these two methods was $93 \%$ which was found to be good.
\end{abstract}

\section{Introduction}

Food quality is the most important factor for any manufacturing requirement because food consumed undergoes contamination from the farm to the industrial manufacturing process. Chemical and microbiological analysis is being periodically done to check food quality, which requires sample preparation, pretreatment being required and most expensive process. Therefore, biosensors can resolve all this by checking quality quickly and at reception or a place where the quality needs to be detected [1]. The recent trend in analytical chemistry is going towards developing electrochemical devices, which are easy for portability, rapid detection, cost-effectiveness, selectivity, sensitivity, less space requirement, and minimal power [2]. Three-electrode systems have been developed to find the triglyceride content $[3,4]$. The three-electrode system is difficult for portability and carrying to a measurement point because the three-electrode system contains three electrodes fabricated separately and needs $10 \mathrm{ml}$ of sample to analyze the quantity of any compound present in the sample.

Screen printing technology is a well-established technique for fabrication of electrochemical sensors, which have high selectivity and sensitivity [5]. Screen-printed electrodes can be made from rigid substances to flexible materials as it can be printed on a flexible PET film as substances. Screen- printed electrodes not only reduce the cost of manufacturing but can also be made of a variety of electrode materials that can measure in a highly reproducible manner [6]. Electrochemical analysis, such as amperometric detection, has increasing popularity in detecting the quality of food products because of the very little time needed for sample preparation and detection of low amounts [7].

Coconut milk is an aqueous solution which is used in cuisines in the south and various parts of the world for various industries including bakeries, confectionaries, ice cream, and biscuit industries to enhance the taste and flavour of various products all around the world, which is extracted from solid endosperm of coconut $[8,9]$. The coconut milk is highly susceptible to both chemical and biochemical spoilage that occurs through oxidation due to the presence of high oil content in it. The oxidation occurs through the breakdown of triglycerides into glycerol and free fatty acid, which is catalyzed by lipase enzyme. As there will be triglyceride breakdown, there is an increase in free fatty acid content in coconut milk. Triglycerides are natural fats made up of a total of three fatty acids and one glycerol molecule $[4,10]$. Therefore, the amount of triglyceride content will be helpful to determine the quality of coconut milk, as triglycerides break down, then free fatty acid content will be increased [11]. In this research work, a screen-printed 


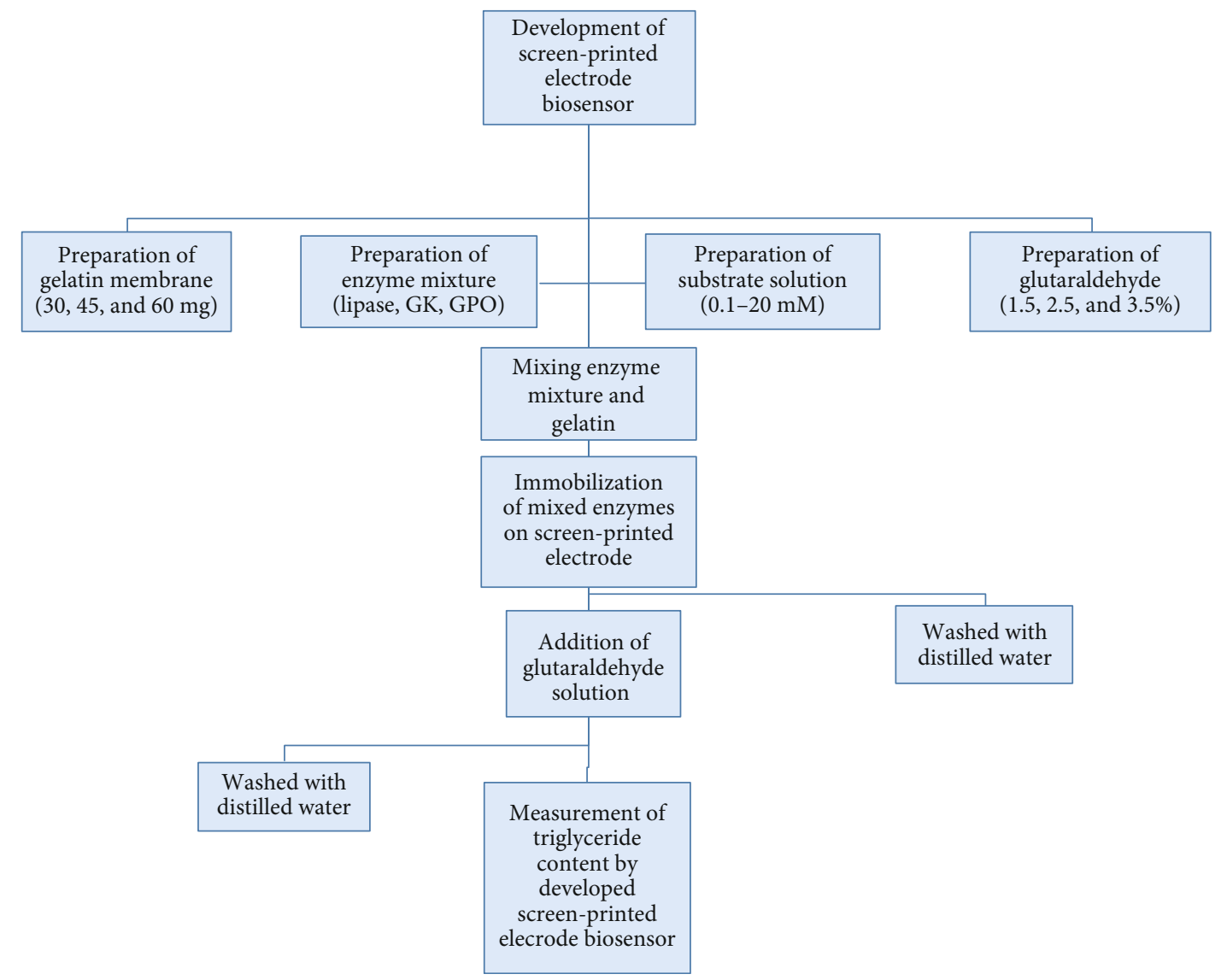

FIgURE 1: Process flowchart for the development of the screen-printed electrode biosensor.

electrode biosensor was developed to detect the amount of triglyceride content present in coconut milk.

\section{Materials and Methods}

2.1. Reagents and Materials. All reagents were purchased from Sigma Aldrich-Merck (Bengaluru, India) of analytical grade: C. rugosa lipase (E.C.3.1.1.3), glycerol-3-phosphate oxidase (Aerococcus viridans) (E.C.1.1.3.21), glycerol kinase (Cellulomonas sp.) (E.C.2.7.1.30), triolein (Y0001113), Triton X-100 (9002-93-1), and ATP. Fresh coconut milk was extracted from fresh coconut meat [12]. The sodium phosphate buffer solution was prepared, as described [13].

Potentiostat/Galvanostat/impedance analyzer (PalmSens 4) was purchased from PalmSens (Netherlands). For the screen-printed electrode, the working electrode was made of carbon, the reference electrode is made of $\mathrm{Ag} / \mathrm{Ag} \mathrm{Cl}$, and the counter electrode is made of carbon with no surface modification and the supporting material was alumina ceramic which was purchased from Class One Systems (New Delhi, India) and used for amperometric detection of triglycerides.

2.2. Methodology for the Development of the Screen-Printed Electrode Biosensor. The methodology for the preparation of screen-printed electrode is explained in Figure 1.

2.3. Preparation of Gelatin Membrane. Gelatin and BSA $(30 \mathrm{mg})$ were added to $300 \mu \mathrm{l}$ of $0.1 \mathrm{M}$ sodium phosphate buffer solution, and then, $31.5 \mu \mathrm{l}$ of $\mathrm{MgCl}_{2}$ was added to the mixture. The prepared solution was kept in the atmosphere for $10 \mathrm{~min}$, and it was homogenized. A mixture of lipase, GPO, and GK has been coimmobilized into gelatin membrane solution through glutaraldehyde cross-linking. Here, one $-\mathrm{CHO}$ group was bound to $-\mathrm{NH}_{2}$ groups of BSA and another $-\mathrm{CHO}$ group of glutaraldehyde linked to $-\mathrm{NH}_{2}$ group of the enzyme [14].

2.4. Preparation of Triolein Solution. Triolein was used as a substrate for the enzyme lipase, GPO, and GK. The solution was prepared at nine different concentrations from initial concentration $0.1 \mathrm{mM}$ to final concentration $20 \mathrm{Mm}$. The solution was prepared using a $0.1 \mathrm{M}$ sodium phosphate buffer solution and stored at the refrigerated condition for further use [3].

2.5. Assay of a Mixture of Lipase, GPO, and GK. The enzyme solution of lipase, GK, and GPO was prepared by adding $1 \mathrm{mg}$ of the enzyme into $1 \mathrm{ml}$ of $0.1 \mathrm{M}$ sodium phosphate buffer solution. From this, $300 \mu \mathrm{l}$ of lipase solution, $150 \mu \mathrm{l}$ of GK, and $60 \mu \mathrm{l} \mathrm{GPO}$ were added in a ratio of $10: 5: 2$ to form a mixed enzyme solution. The enzyme mixture also consists of ATP and $\mathrm{MgCl}_{2}$, which were prepared up to $10 \mu \mathrm{l}$ and added to the prepared enzyme mixture [4].

2.6. Construction of the Screen-Printed Electrode Biosensor. An amperometric biosensor for measuring triglyceride in 


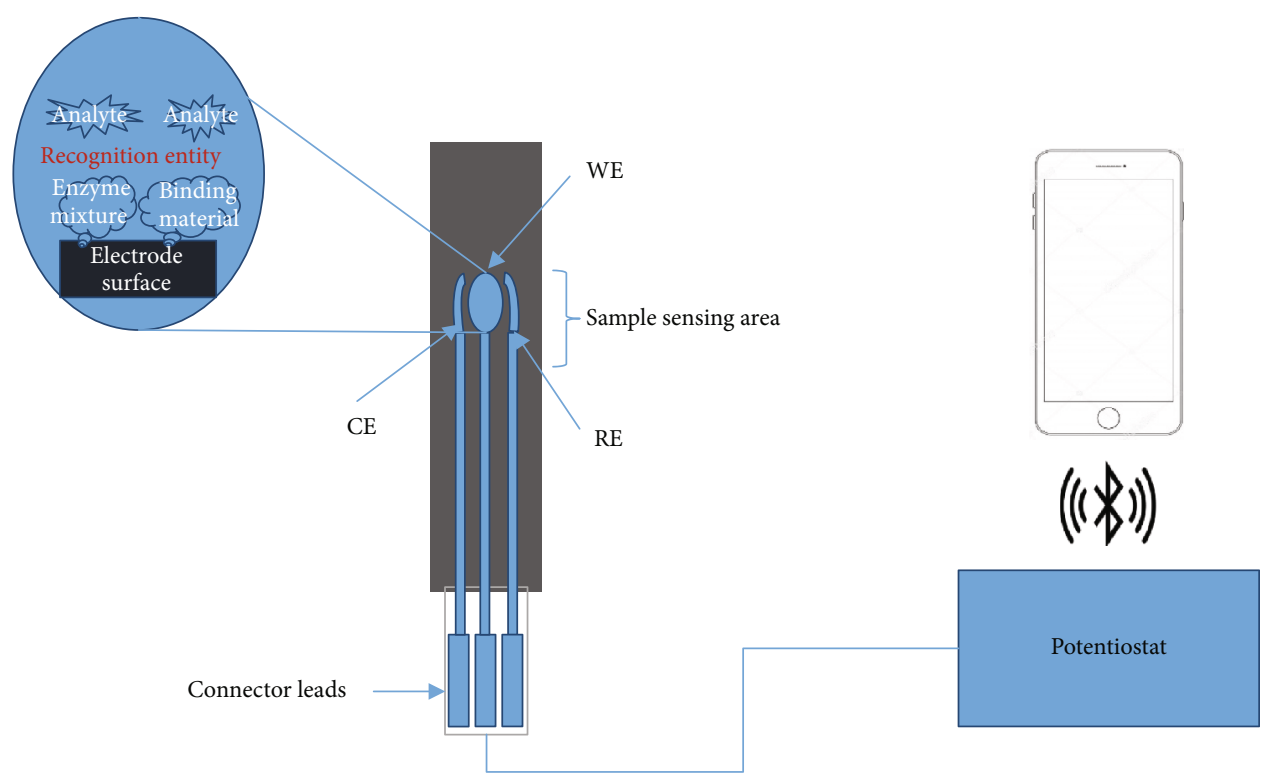

FIGURE 2: Schematic representation of the screen-printed electrode biosensor.

coconut milk was constructed by adding $40 \mu$ l of enzyme mixture, which contains lipase, GPO, and GK, mixed with $10 \mu \mathrm{l}$ of gelatin solution, and the enzyme mixture solution was then poured onto the working electrode and kept at $4^{\circ} \mathrm{C}$ for $30 \mathrm{~min}$. The screen-printed electrode was then taken out, and again, 2.5\% glutaraldehyde solution was poured onto the working electrode for $5 \mathrm{~min}$ for cross-linking, and then, the screen-printed electrode surface was washed using distilled water as explained in the flowchart in Figure 1. The constructed screen-printed electrode biosensor was taken for measurement to reaction cell connected to the potentiostat, as shown in Figure 2.

All the experiments were carried out at room temperature, and the current was measured for different triolein concentrations. The working electrodes were polarized at $0.4 \mathrm{~V}$ potential, and the current was measured amperometrically [15]. The reaction occurs as soon as triolein was added due to coimmobilized lipase enzyme, GPO, and GK. After triolein was added, it is then converted into dihydroxyacetone phosphate and $\mathrm{H}_{2} \mathrm{O}_{2}$. Then, $\mathrm{H}_{2} \mathrm{O}_{2}$ will split under potential applied through potentiostat, and then, the electrons were generated from $\mathrm{H}_{2} \mathrm{O}_{2}$ which passed to the counter electrode [16]. The reactions involved are as follows;

$$
\begin{gathered}
\text { triglyceride } \stackrel{\text { lipase }}{\longrightarrow} \text { glycerol + fatty acids } \\
\text { glycerol + ATP } \stackrel{\mathrm{GK} \mathrm{MgCl}_{2}}{\longrightarrow} \propto \text {-glycerol-3-phosphate + ADP }
\end{gathered}
$$

glycerol-3-phosphate $+\mathrm{O}_{2} \stackrel{\text { GPO }}{\longrightarrow}$ Dihydroxyacetone phosphate $+\mathrm{H}_{2} \mathrm{O}_{2}$

$$
\mathrm{H}_{2} \mathrm{O}_{2} \longrightarrow 2 \mathrm{H}^{+}+\mathrm{O}_{2}+2 \mathrm{e}^{-}
$$

\subsection{Experimental Procedure}

2.7.1. Effect of the Amount of Gelatin on the Screen-Printed Electrode Biosensor. To study the effect of the amount of gel- atin on the screen-printed electrode, three different gelatin concentrations $(30,45$, and $30 \mathrm{mg}$ ) were taken, and enzyme mixture and glutaraldehyde concentration were kept constant. The working electrode was immobilized with different amounts of gelatin and response was noted.

2.7.2. Effect of Glutaraldehyde Concentration on the ScreenPrinted Electrode Biosensor. The three different varying concentrations of $1.5,2.5$, and $3.5 \%$ of glutaraldehyde solution were taken, and the effect on the screen-printed electrode biosensor response was found. The enzyme mixture and amount of gelatin concentration were kept constant.

2.7.3. Effect of pH on the Screen-Printed Electrode Biosensor. Reaction buffer solution with $\mathrm{pH}$ ranges from 4.0 to 9.0 was made to study the effect on screen-printed biosensor response. The citric acid solution was added to $10 \mathrm{ml}$ of sodium phosphate buffer solution to maintain the low $\mathrm{pH}$ range from 4.0 to7.0, and for high $\mathrm{pH}$ from 7.0 to 9.0, glycine solution was added. Enzyme mixture, amount of gelatin, and concentration of glutaraldehyde solution were kept constant. The output current for each $\mathrm{pH}$ condition was noted for a $5 \mathrm{mM}$ triolein solution.

2.7.4. Development of the Correlation between Triolein and the Output Current. For the readings for output current produced during the electrochemical reaction between enzymes, the sample was taken using a biosensor, and the amount of triglyceride was calculated using an empirical relation obtained.

2.7.5. Triglyceride Measurement in Coconut Milk. To find the triglyceride content in coconut milk, $5 \mathrm{ml}$ of milk was mixed with $10 \mathrm{ml}$ of $0.1 \mathrm{M}$ sodium phosphate buffer. Triton X-100 solution was added into this mixture, as it acts as an emulsifying agent. 


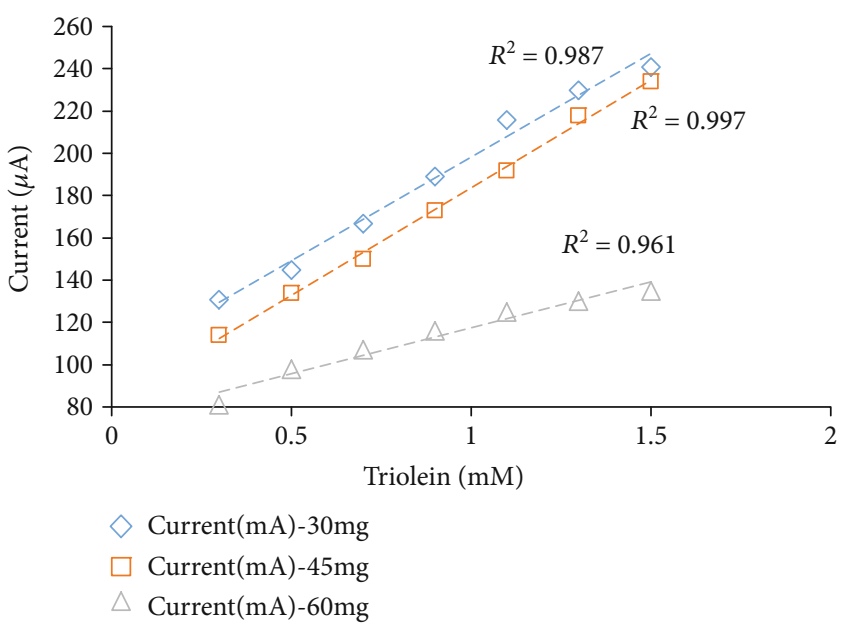

FIGURE 3: The effect of the amount of gelatin concentration on biosensor response.

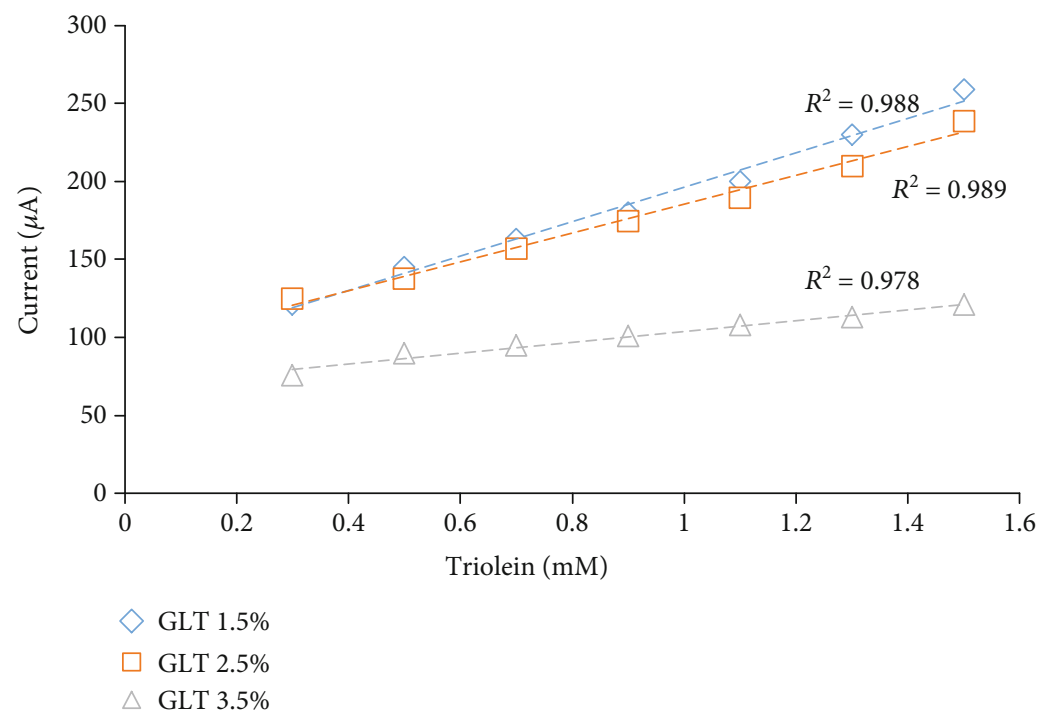

FIGURE 4: The effect of glutaraldehyde content on biosensor response.

2.7.6. Validation of the Developed Screen-Printed Electrode Biosensor. Validation of the developed biosensor was done by using ultrahigh-performance liquid chromatography (UHPLC). UHPLC system (Shimadzu Corporation, Japan) equipped with column: Shim-pack XR-ODS III $(100 \times 2 \mathrm{~mm}, 2.2 \mu \mathrm{m}$ particle size $)$, column temperature $40^{\circ} \mathrm{C}$, flow rate $0.3 \mathrm{ml} / \mathrm{min}$, injection volume $5 \mu \mathrm{l}$ was used. Mobile Phase ACN/MeOH/THF (40:40:20 v/v/v) with the injection volume was $40 \mu \mathrm{l}$, and samples were eluted at a flow rate of $1 \mathrm{ml} / \mathrm{min}$.

\section{Results and Discussion}

3.1. Effect of the Amount of Gelatin on Biosensor Response. Among the three different amounts of gelatin, $45 \mathrm{mg}$ was found to be giving the best results for biosensor response, linearity, and $R^{2}$ values. The results obtained are given in Figure 3. In $30 \mathrm{mg}$ gelatin concentration, the substrate may leach out easily, and a higher concentration of $60 \mathrm{mg}$ gelatin bioactive layer increases and makes it harder for the substrate to pass through a gelatin membrane. Thus, lower $R^{2}$ and biosensor responses were obtained. A previous research also found a similar kind of result for the gelatin membrane [14], polyvinyl chloride membrane [17], and cellulose acetate membrane [18].

3.2. Effect of Glutaraldehyde Content on Biosensor Response. The optimum results were obtained for $2.5 \%$ glutaraldehyde concentration, which is shown in Figure 4 . In the case of low glutaraldehyde concentration of $1.5 \%$ which made a substrate to leak out easily from the gelatin membrane due to fewer cross-linking with gelatin membrane and for a high concentration of $3.5 \%$, biosensor response was less due to more cross-link, which prevents the substrate from passing through a gelatin membrane. Similar results were obtained 


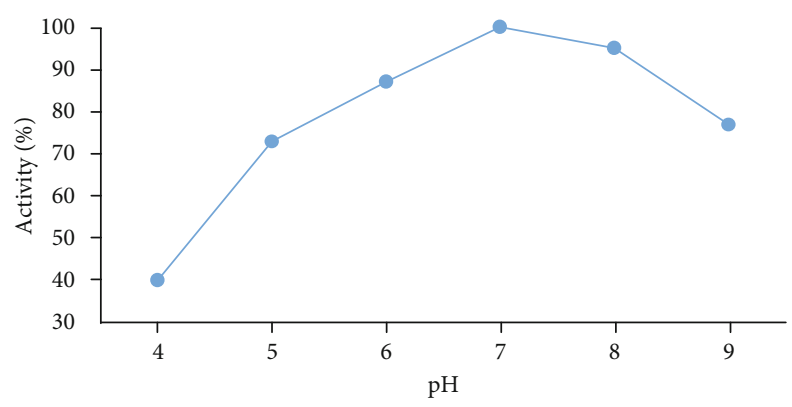

Figure 5: The effect of $\mathrm{pH}$ on biosensor response.

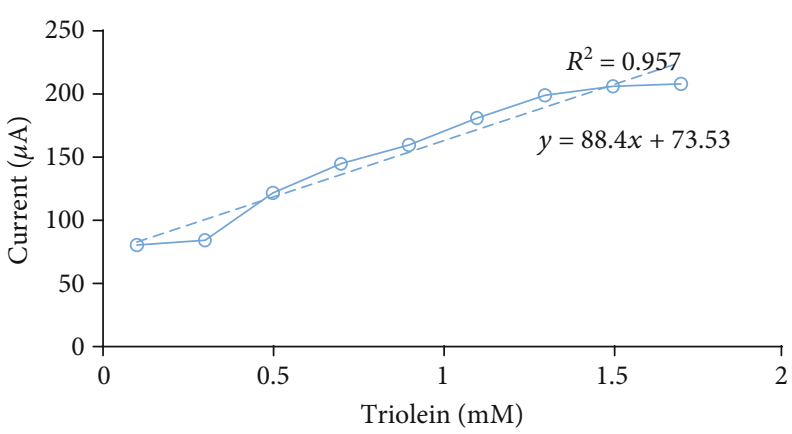

Figure 6: The calibration curve for the developed biosensor.

for acrylamide determination for French fries [19] and serum triglyceride determination [3].

3.3. Effect of pH on Biosensor Response. The buffer solution of different $\mathrm{pH}$ was made to see the effect on biosensor response, and it is shown in Figure 5. The biosensor response was found to be high for $\mathrm{pH} 7$ and found to be low for other $\mathrm{pH}$ solutions. For $\mathrm{pH} 7.0$, we can see the maximum current obtained which is plotted in the graph (current vs. $\mathrm{pH}$ ). As a slight increase or decrease in $\mathrm{pH}$ could attribute to the changed micro environmental and differential folding of enzymes in the reaction, hence, the maximum current obtained has been accepted to have maximum activity. Different research has similar research for potentiometric biosensor $7.0 \mathrm{pH}$ [20] and oxygen meter-based biosensor $8.0 \mathrm{pH}[21]$.

3.4. Effect of Substrate Concentration and Development of Correlation between Triolein and Output Current. Different triolein concentrations ranging from $0.1 \mathrm{mM}$ to $1.7 \mathrm{mM}$ were taken to find a biosensor response. The experiment was conducted in $10 \mathrm{ml}$ final reaction volume in $0.1 \mathrm{M}$ phosphate buffer, in which $\mathrm{pH}$ is 7.0. The graph was plotted for a prepared biosensor. The linearity was obtained from $0.1 \mathrm{mM}$ to $1.5 \mathrm{mM}$ defined by the equation $y=88.417 x+73.536$ $(R=0.952)$, which is shown in Figure 6. There is a deviation from linearity for higher concentrations which may be due to an insufficient amount of dissolved oxygen, which is cosubstrate to an enzyme or a limited amount of enzymes in bioactive material. Similar results were obtained for PVC membrane-based biosensor (5-2.1 mM) [17], silicon-based biosensor (0.2-2.1 mM), cellulose acetate-bound enzyme- based biosensor (0.2-3.5 mM) [20], and dissolved oxygen biosensor (5-2.0 Mm) [22].

3.5. Reproducibility. The reproducibility was tested for a total of three average standard solutions, which contain the same amount of triolein concentration of $0.5 \mathrm{mM}$. The standard deviation, variation of the coefficient, and average value were calculated as $0.083 \times 10^{-3} \mathrm{mM}, 11.97 \%(n=3)$.

3.6. Validation of the Developed Biosensor. To study the accuracy of the present method, triglyceride detection from the high-performance liquid chromatography method [23] for coconut milk with different storage periods along with the present method was performed. The values obtained by both methods showed a good correlation $r=0.93$, which is shown in Figure 7.

3.7. Detection of Triglyceride Content in Coconut Milk. The developed screen-printed electrode biosensor was applied to detect the amount of triglyceride in coconut milk. $5 \mathrm{ml}$ of milk was mixed with $10 \mathrm{ml}$ of $0.1 \mathrm{M}$ sodium phosphate buffer. Then, the solution was taken into a reaction mixture, and the output current was measured for the $5^{\text {th }}$, $10^{\text {th }}$, and $15^{\text {th }}$ hour. The triglyceride content of the same coconut sample was measured using the UHPLC method. The results obtained by both methods were compared in Figure 7.

\section{Conclusions}

An amperometric screen-printed electrode biosensor was constructed to find the triglyceride content in coconut 


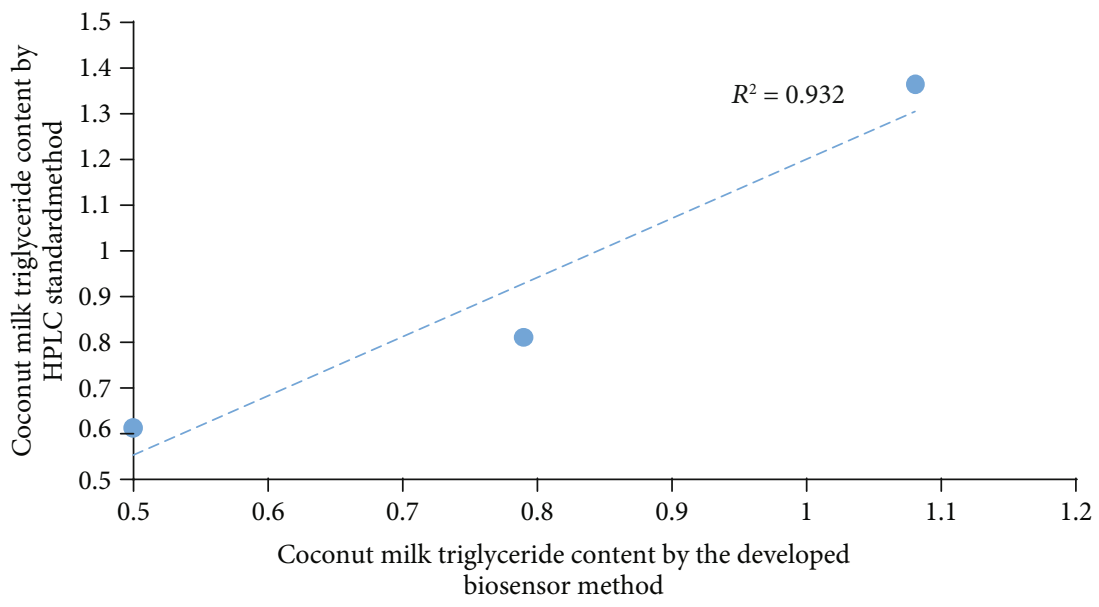

Figure 7: Correlation between the developed biosensor method and the standard HPLC method.

milk. The enzyme lipase, GK, and GPO were immobilized into a gelatin membrane. Then, the enzyme mixture was poured onto the working electrode. Then, the screenprinted electrode was connected to potentiostat for measurement of output current. The current measured was linear to the amount of triolein concentration.

\section{Data Availability}

The data used to support the findings of this study are included in the article.

\section{Conflicts of Interest}

The authors declare that there is no conflict of interest regarding the publication of this paper.

\section{Acknowledgments}

The authors express their thanks to the Director, Indian Institute of Food Processing Technology, Thanjavur, for his unremitting encouragement.

\section{References}

[1] G. Murugaboopathi, V. Parthasarathy, C. Chellaram, T. P. Anand, and S. Vinurajkumar, "Applications of biosensors in food industry," Biosciences Biotechnology Research Asia, vol. 10, no. 2, pp. 711-714, 2013.

[2] K. C. Honeychurch and J. P. Hart, "Screen-printed electrochemical sensors for monitoring metal pollutants," $\operatorname{Tr} A C$ Trends in Analytical Chemistry, vol. 22, no. 7, pp. 456-469, 2003.

[3] C. S. Pundir, B. S. Singh, and J. Narang, "Construction of an amperometric triglyceride biosensor using PVA membrane bound enzymes," Clinical Biochemistry, vol. 43, no. 4-5, pp. 467-472, 2010.

[4] C. Pundir and V. Narwal, "Biosensing methods for determination of triglycerides: a review," Biosensors and Bioelectronics, vol. 100, pp. 214-227, 2018.
[5] N. J. Ronkainen, H. B. Halsall, and W. R. Heineman, "Electrochemical biosensors," Chemical Society Reviews, vol. 39, no. 5, pp. 1747-1763, 2010.

[6] N. Thiyagarajan, J. L. Chang, K. Senthilkumar, and J. M. Zen, "Disposable electrochemical sensors: a mini review," Electrochemistry Communications, vol. 38, pp. 86-90, 2014.

[7] J. K. Jadav, V. V. Umrania, K. J. Rathod, and B. A. Golakiya, "Development of silver/carbon screen-printed electrode for rapid determination of vitamin C from fruit juices," $L W T$, vol. 88, pp. 152-158, 2018.

[8] C. C. Seow and C. N. Gwee, "Coconut milk: chemistry and technology," International Journal of Food Science \& Technology, vol. 32, no. 3, pp. 189-201, 1997.

[9] A. Tansakul and P. Chaisawang, "Thermophysical properties of coconut milk," Journal of Food Engineering, vol. 73, no. 3, pp. 276-280, 2006.

[10] C. Pundir and J. Narang, "Determination of triglycerides with special emphasis on biosensors: a review," International Journal of Biological Macromolecules, vol. 61, pp. 379-389, 2013.

[11] P. Fox, "Indigenous enzymes in milk," in Advanced dairy chemistry-1 proteins, pp. 467-471, Springer, 2003.

[12] C. Arumughan, C. Balachandran, and A. Sundaresan, "Development of a process for coconut cream on commercial scale," Journal of Food Science and Technology, vol. 30, pp. 408-412, 1993.

[13] G. Gómez, M. J. Pikal, and N. Rodríguez-Hornedo, "Effect of initial buffer composition on $\mathrm{pH}$ changes during farfrom-equilibrium freezing of sodium phosphate buffer solutions," Pharmaceutical Research, vol. 18, no. 1, pp. 90-97, 2001.

[14] A. Yücel, H. M. Özcan, and A. Sağıroğlu, "A new multienzyme-type biosensor for triglyceride determination," Preparative Biochemistry and Biotechnology, vol. 46, no. 1, pp. 78-84, 2016.

[15] S. A. Rothwell, S. J. Killoran, and R. D. O’Neill, “Enzyme immobilization strategies and electropolymerization conditions to control sensitivity and selectivity parameters of a polymer-enzyme composite glucose biosensor," Sensors, vol. 10, no. 7, pp. 6439-6462, 2010.

[16] M. Schoemaker, R. Feldbrügge, B. Gründig, and F. Spener, "The lipoxygenase sensor, a new approach in essential fatty 
acid determination in foods," Biosensors and Bioelectronics, vol. 12, no. 11, pp. 1089-1099, 1997.

[17] J. Narang, Minakshi, M. Bhambi, and C. S. Pundir, "Fabrication of an amperometric triglyceride biosensor based on PVC membrane," Analytical Letters, vol. 43, no. 1, pp. 1-11, 2009.

[18] Minakshi and C. S. Pundir, "Construction of an amperometric enzymic sensor for triglyceride determination," Sensors and Actuators B: Chemical, vol. 133, no. 1, pp. 251-255, 2008.

[19] E. Tareke, P. Rydberg, P. Karlsson, S. Eriksson, and M. Törnqvist, "Analysis of acrylamide, a carcinogen formed in heated foodstuffs," Journal of Agricultural and Food Chemistry, vol. 50, no. 17, pp. 4998-5006, 2002.

[20] R. R. K. Reddy, A. Chadha, and E. Bhattacharya, "Porous silicon based potentiometric triglyceride biosensor," Biosensors and Bioelectronics, vol. 16, no. 4-5, pp. 313-317, 2001.

[21] T. A. Kelly and G. D. Christian, "Amperometric determination of glycerol and triglycerides using an oxygen electrode," Analyst, vol. 109, no. 4, pp. 453-456, 1984.

[22] M. Bhambi and C. Pundir, "Preparation of oxygen meter based biosensor for determination of triglyceride in serum," Sensors and Transducers, vol. 67, no. 5, pp. 561-567, 2006.

[23] K. W. Y. Lee, C. J. H. Porter, and B. J. Boyd, "A simple quantitative approach for the determination of long and medium chain lipids in bio-relevant matrices by high performance liquid chromatography with refractive index detection," AAPS PharmSciTech, vol. 14, no. 3, pp. 927-934, 2013. 